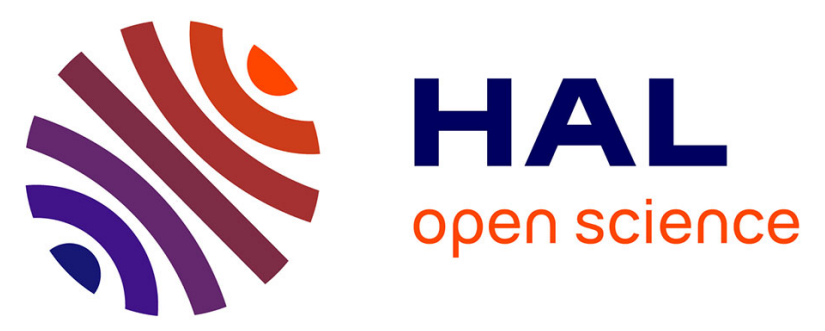

\title{
Origin of compositional differences in organic matter abundance and oil potential of cherty and clayey Cenomanian black levels in the Umbria-Marche basin (Italy).
}

V. Salmon, Sylvie Derenne, Elisabeth Lallier-Vergès, Jacques Connan, A. Kahn-Harari, C. Largeau

\section{To cite this version:}

V. Salmon, Sylvie Derenne, Elisabeth Lallier-Vergès, Jacques Connan, A. Kahn-Harari, et al.. Origin of compositional differences in organic matter abundance and oil potential of cherty and clayey Cenomanian black levels in the Umbria-Marche basin (Italy).. Organic Geochemistry, 2003, 34, pp.12371245. 10.1016/S0146-6380(03)00117-7 . hal-00069422

\section{HAL Id: hal-00069422 \\ https://hal-insu.archives-ouvertes.fr/hal-00069422}

Submitted on 8 Aug 2006

HAL is a multi-disciplinary open access archive for the deposit and dissemination of scientific research documents, whether they are published or not. The documents may come from teaching and research institutions in France or abroad, or from public or private research centers.
L'archive ouverte pluridisciplinaire HAL, est destinée au dépôt et à la diffusion de documents scientifiques de niveau recherche, publiés ou non, émanant des établissements d'enseignement et de recherche français ou étrangers, des laboratoires publics ou privés. 


\title{
Origin of compositional differences in organic matter abundance and oil potential of cherty and clayey Cenomanian black levels in the Umbria-Marche basin (Italy)
}

\author{
V. Salmon ${ }^{a}$, S. Derenne ${ }^{a}$, E. Lallier-Vergès ${ }^{b}$, J. Connan $^{c}$, A. Kahn-Harari ${ }^{\mathrm{d}}$ and \\ C. Largeau ${ }^{\text {a }}$ \\ ${ }^{a}$ LCBOP, UMR CNRS/ENSCP 7573, 11 rue P. \& M. Curie, 75231, Paris Cedex 05, France \\ ${ }^{\mathrm{b}}$ ISTO, UMR CNRS/Université d' Orléans 6113, Orléans, France \\ ${ }^{\mathrm{c}}$ Elf Aquitaine, CSTJF, Pau, France \\ ${ }^{\mathrm{d}}$ LCAS, UMR CNRS/ENSCP 7574, 11 rue P. \& M. Curie, 75231, Paris Cedex 05, France
}

\section{Abstract}

Rock-Eval pyrolysis of a large set of Cenomanian samples, collected from the black levels (clayey, cherty and mixed) in three sections of the Umbria-Marche basin, showed large differences in organic matter $(\mathrm{OM})$ quantity and quality. The chert samples systematically exhibit much lower TOC contents, markedly lower HI and higher OI. This reflects the extensive oxidative destruction of the initial kerogen that occurred upon the chertification of some clayey sediments. A comparative study, by a combination of microscopic, spectroscopic and pyrolytic methods, was performed on kerogens of the chert and clay layers of a representative mixed level. The various fractions of the initial kerogen underwent differential destruction or alteration during chertification, resulting in (i) relative enrichments of microfossils and woody debris although lignin was altered by demethoxylation and (ii) extensive destruction of the amorphous fraction while it remained predominant. The amorphous fraction retained in the chert kerogen showed large changes in composition related to oxygen incorporation and probably escaped complete destruction owing to oxidative reticulation. The above features account for the pronounced systematic differences in $\mathrm{OM}$ abundance and oil potential between the chert and clay layers in the black levels.

\section{Introduction}

A number of black levels (laterally extensive, dark coloured, clay- or chert-rich horizons intercalated with pale-coloured pelagic limestones) occur just below the Cenomanian/Turonian boundary (ca. 93.3 Ma) in the Umbria-Marche basin, Central Italy ([Arthur and Premoli, 1982 and Beaudoin et al]). Approximately 40 of the levels have been identified and correlated in numerous sections over the entire basin ( [Beaudoin et al]). These levels are relatively thin $(<1 \mathrm{~cm}$ up to ca. $15 \mathrm{~cm})$ and their deposition spanned about 2.5 million years ( [Arthur and Premoli, 1982, M'ban, 1994 and Beaudoin et al]). The black levels exhibit rhythmic deposition whose observed cyclicity can be related to precession ( [Beaudoin et al]) as previously observed in other deposits (e.g. [Klemme and Ulmishek, 1991 and de Boer and Smith, 1994]). Such levels occur within predominantly organic-lean carbonate sediments and exhibit a clayey or siliceous lithology. Some mixed levels showing both types of lithology are also observed, with the siliceous (chert) layers always overlaying the clay ones. 
Sedimentological field observations and morphological studies on whole rock samples ([Salmon, 1999]) indicate that the chert levels (layers) result from the complete (partial) chertification of clay sediments. Accordingly, the organic matter (OM) in the chert and clay layers of a mixed level share a common origin. It also appeared that this transformation into chert took place at a relatively early stage of sediment compaction. As observed in other deposits, oxygen and silica for chertification could be supplied by clay ( [Behl, 1990]); radiolarian tests were probably another important potential source of silica through dissolution and recrystallisation. Cherts generally exhibit low contents of OM, as observed for example in Cretaceous deposits from South America ( [Marcellari and de Vries, 1987]) and laboratory studies on simulated silicification of blue green algae ( [Oehler, 1976]) showed that extensive OM destruction took place due to the intense oxidation processes associated with chert formation. Indeed, (i) examination of a set of thirteen samples from black levels from the Furlo section in the Umbria-Marche Basin showed large differences in OM quantity and quality, with total organic carbon (TOC) ranging from ca. 0.5 to $14 \%$ and Rock-Eval Hydrogen Index (HI) from ca. 120 to $450 \mathrm{mg} \mathrm{HC} / \mathrm{g}$ TOC ( [M'ban, 1994]) and (ii) these observations pointed to correlations between the above features and the lithology of the black levels, the cherts generally exhibiting markedly lower TOC contents $(<1 \%)$ and HI values (commonly $<200 \mathrm{mgHC} / \mathrm{g}$ TOC) when compared to the clays.

In the present work a larger set of samples, collected from the black levels (clay, chert, mixed) of three sections in the Umbria-Marche Basin, was examined by Rock-Eval pyrolysis. These bulk analyses confirmed the occurrence of conspicuous differences in OM abundance and oil potential between the clay and chert samples. Such differences are well illustrated by the samples from the chert and clay layers from a mixed black level, termed NN8, from the Sta Maria di Burano (SMB) section. A detailed study was, therefore, performed on the kerogen isolated from the chert layer (NN8si) of this mixed level, via a combination of microscopic (transmitted light microscopy, transmission electron microscopy), spectroscopic (FTIR and solid state ${ }^{13} \mathrm{C} \mathrm{NMR}$ ) and pyrolytic methods, to determine its composition. Comparison with previous observations ([Salmon et al and Salmon et al]) on the kerogen from the associated clay layer $(\mathrm{NN} 8 \mathrm{c})$ afforded information on the origin of the compositional differences observed between the clay and chert samples in the black levels of the basin.

\section{Materials and methods}

\subsection{Rock-Eval analysis of whole rock samples}

Forty-eight samples, from 34 black levels (including 14 mixed levels), were collected from three sections located north of Perugia (Italy): the SMB section (ca. $40 \mathrm{~km}$ ), the Furlo section (ca. $65 \mathrm{~km}$ ) and the Monte Petrano section (ca. $90 \mathrm{~km}$ ). Rock-Eval pyrolyses were performed on ca. $90 \mathrm{mg}$ of ground rock with a temperature program from $300{ }^{\circ} \mathrm{C}(20 \mathrm{~min})$ up to $600{ }^{\circ} \mathrm{C}$ at $25^{\circ} \mathrm{C} / \mathrm{min}$ under a He flow, followed by oxidation at $600{ }^{\circ} \mathrm{C}$ for 7 min under an oxygen flow.

\subsection{Study of the chert kerogen}

The NN8 level in the SMB section consists of a $3 \mathrm{~cm}$ thick clay layer overlain by a $2 \mathrm{~cm}$ thick chert layer. This black level spans a large area in the Umbria-Marche basin and was identified in all the known outcrops over the whole basin ([Beaudoin et al]). Vitrinite reflectance $(0.55 \%)$ indicated a relatively low maturity corresponding to the onset of the oil window ( 
[Salmon, 1999]). The NN8si sample was taken from a fresh surface of the section in an active quarry. This siliceous sample was collected in the first centimeter of the base of the cherty layer of the NN8 black level just above the previously studied clayey sample (NN8c). The kerogen concentrate was prepared via the classical $\mathrm{HF} / \mathrm{HCl}$ treatment ( [Durand and Nicaise, 1980]) and was immediately analysed to avoid possible alteration upon storage ( [Salmon et al]).

Rock-Eval pyrolysis was performed on ca. $5 \mathrm{mg}$ of NN8si and NN8c kerogen concentrates using the same conditions as above for whole rock samples. Elemental composition was determined at the Service Central d'analyse of the CNRS (Vernaison) by combustion at $1050{ }^{\circ} \mathrm{C}$ under $\mathrm{O}_{2}$.

X-ray diffraction powder patterns were recorded at room temperature, with a SIEMENS D5000 diffractometer ( $\mathrm{CoK}_{\alpha}$ radiation), equipped with a graphite back monochromator set on the diffracted beam. X-ray data collection (scanning step $0.02^{\circ}$, counting time $2.4 \mathrm{~s}$ ) and data treatment were monitored by the Siemens Diffract-AT routines.

The FTIR spectra were recorded with a Bruker IFS48 spectrometer as $\mathrm{KBr}$ pellets and the cross polarization/magic angle spinning (CP/MAS) ${ }^{13} \mathrm{C}$ NMR spectra were obtained on a Bruker MSL 400 under the same conditions as previously described ([Salmon et al]).

A Leitz MPVII microscope was used for transmitted light microscopy observations. The relative abundance of the main types of particles in the clay and chert kerogens was determined through area estimation on 500 particles per slide. Transmission electron microscopy (TEM) observations were performed as previously described ([Boussafir et al]) using a Philips CM 20 microscope.

Off-line pyrolysis under a helium flow and pyrolysate separation by column chromatography were performed as described in [Largeau et al]. The methanol-eluted fraction was esterified to improve fatty acid detection. Each fraction was analysed by combined gas chromatography/mass spectrometry (GC/MS) as described in [Salmon et al].

\section{Results and discussion}

\subsection{Rock-Eval analysis of whole rocks}

The Rock-Eval data obtained for the 48 samples, collected from homogeneous or mixed black levels, reveal pronounced differences between the clay and chert rocks (Table 1, Fig. 1). Thus, TOC is markedly lower in the latter (systematically below 1\%), whereas most of the clays exhibit values above $10 \%$. The $\mathrm{HI}$ is markedly higher for the clays, whereas the reverse is observed for the oxygen index (OI). HI and OI values of kerogens are controlled by different factors, including kerogen maturity, type and level of oxidation ([Tissot and Welte, 1984]). In the present study the former factor can be ruled out since the black levels experienced close (identical for the mixed levels) thermal histories in terms of burial. The second factor can also be straightforwardly eliminated, at least for the mixed levels since the $\mathrm{OM}$ in the chert and clay layers has a common origin. Accordingly, in agreement with general observations on cherts and laboratory silicification mentioned in the Introduction, the large differences observed for the HI and OI values between the chert and clay samples must reflect differences in post-depositional oxidation associated with chert formation. 
Table 1. Rock-Eval data for whole samples from black levels of the Sta maria di Burano (SMB), Furlo (FU) and Monte Petrano (MP) sections

\begin{tabular}{|c|c|c|c|}
\hline Sample $^{\mathrm{a}}$ & $\mathrm{TOC}^{\mathrm{b}}$ & $\mathrm{HI}^{\mathrm{b}}$ & $\mathrm{OI}^{\mathrm{b}}$ \\
\hline \multicolumn{4}{|c|}{ SMB section } \\
\hline $\begin{array}{l}\text { (NN1si) } \\
\left(N_{2} \text {;i) }\right.\end{array}$ & 0.5 & 107 & $\begin{array}{l}60 \\
54\end{array}$ \\
\hline (NN2si) & 0.7 & 152 & \\
\hline (NN3c) & 11.2 & 418 & 7 \\
\hline$(N N 3 s i)$ & 0.1 & $n d$ & $n d$ \\
\hline (NN4si) & 0.3 & nd & nd \\
\hline (NN5c) & 8.8 & 375 & 9 \\
\hline (NN6c) & 12.2 & 427 & 12 \\
\hline (NN7c) & 13.2 & 452 & 7 \\
\hline (NN8c) & 13.6 & 449 & 7 \\
\hline$(N N 8 s i)$ & 0.2 & nd & $n d$ \\
\hline$(\mathrm{NN} 9 \mathrm{c})$ & 10.7 & 362 & 11 \\
\hline (NN10c) & 10.2 & 436 & 10 \\
\hline (NN10si) & 0.6 & 138 & 48 \\
\hline (NN15si) & 0.4 & 109 & 72 \\
\hline (NN18c) & 12.7 & 359 & 7 \\
\hline (NN18si) & 0.1 & $n d$ & $n d$ \\
\hline (NN19c) & 10.9 & 424 & 10 \\
\hline$(\mathrm{NN} 20 \mathrm{c})$ & 11.6 & 487 & 5 \\
\hline (NN21c) & 13.2 & 469 & 11 \\
\hline$(N N 21 s i)$ & 0.4 & 156 & 68 \\
\hline (NN22c) & 13.8 & 445 & 17 \\
\hline$(N N 22 s i)$ & 0.1 & $n d$ & $n d$ \\
\hline$(\mathrm{NN} 24 \mathrm{c})$ & 9.6 & 337 & 13 \\
\hline$(N N 24 s i)$ & 0.4 & 97 & 53 \\
\hline (NN25si) & 0.2 & nd & nd \\
\hline (NN26si) & 0.1 & nd & nd \\
\hline (NN27si) & 0.1 & nd & nd \\
\hline \multicolumn{4}{|l|}{ FU section } \\
\hline (NN1si) & 0.8 & 179 & 39 \\
\hline$(\mathrm{NN} 3 \mathrm{c})$ & 10.7 & 442 & 6 \\
\hline$(N N 3 s i)$ & 0.2 & nd & nd \\
\hline (NN5c) & 13.5 & 397 & 10 \\
\hline (NN7c) & 9.2 & 379 & 8 \\
\hline$(N N 7 s i)$ & 0.2 & nd & $n d$ \\
\hline (NN8c) & 11.2 & 439 & 7 \\
\hline$(N N 8 s i)$ & 0.1 & $n d$ & $n d$ \\
\hline (NN10c) & 12.8 & 409 & 13 \\
\hline (NN20c) & 8.9 & 349 & 12 \\
\hline (NN21c) & 13.2 & 447 & 8 \\
\hline$(\mathrm{NN} 24 \mathrm{c})$ & 14.8 & 485 & 6 \\
\hline$(N N 24 s i)$ & 0.5 & 122 & 57 \\
\hline \multicolumn{4}{|l|}{ MP section } \\
\hline (NN1si) & 0.2 & nd & nd \\
\hline (NN3c) & 8.2 & 357 & 5 \\
\hline$(N N 3 s i)$ & 0.1 & nd & nd \\
\hline$(\mathrm{NN} 5 \mathrm{c})$ & 12.2 & 427 & 21 \\
\hline (NN5si) & 0.8 & 113 & 61 \\
\hline (NN7si) & 0.4 & 97 & 49 \\
\hline (NN\&c) & 11.9 & 478 & 7 \\
\hline (NN8si) & 0.1 & $n d$ & $n d$ \\
\hline
\end{tabular}




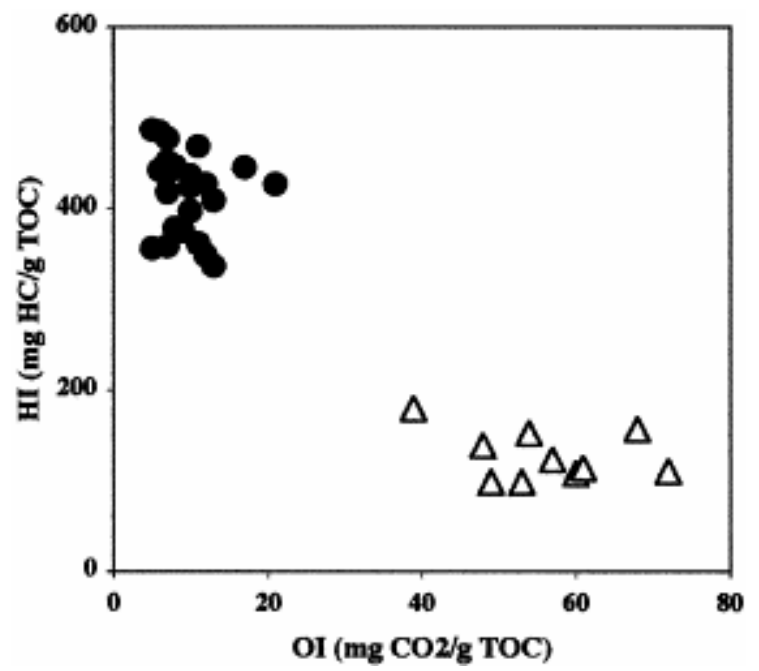

Fig. 1. HI versus OI diagram for whole samples from black levels of the Sta maria di Burano, Furlo and Monte Petrano sections (circles: clayey samples, triangles: cherty samples; empty symbols: TOC $<1 \%$, filled symbols:

TOC around $10-15 \%)$.

The representative NN8 black level was selected for further study so as to derive detailed information on the differences between the chert and clay kerogens and on the consequences of chertification on kerogen composition.

\subsection{Detailed study of the chert kerogen and comparison with the clay kerogen}

\subsubsection{Bulk geochemical features}

Rock-Eval pyrolysis was performed on the kerogen concentrates since significant $\mathrm{HI}$ and OI values cannot reliably be obtained for rocks with a TOC $<0.3 \%$ ([Espitali and Espitali]). The chert kerogen shows a markedly lower oil potential, whereas OI is much higher ( Table 2). Elemental analysis also showed large differences: the chert kerogen exhibits a lower $\mathrm{H} / \mathrm{C}$ atomic ratio, while its $\mathrm{O} / \mathrm{C}$ ratio is ca. two times higher when compared to the clay kerogen (Table 2). In addition, the elemental analysis of the concentrates indicated a markedly lower ash content for the chert. It is well documented that some minerals, including pyrite and various sulfates survive $\mathrm{HF} / \mathrm{HCl}$ treatment ( [Tissot and Welte, 1984]). Pyrite indeed occurs in both concentrates as shown by microscopy and by the presence of a sharp band at $427 \mathrm{~cm}^{-1}$ in their FTIR spectra. Organic sulfur content of kerogens is classically calculated from elemental analysis data on concentrates, by assuming that mineral sulfur only occurs as pyrite and that all the Fe corresponds to pyrite, so that $\mathrm{S}_{\text {org }}=\mathrm{S}_{\text {total }}$ (measured) $-\mathrm{S}_{\text {ash }}$ (pyritic, calculated from $\mathrm{Fe}$ content). Such a calculation showed for the clay kerogen a low sulfur content and a $\mathrm{S}_{\text {org }} / \mathrm{C}$ atomic ratio of 0.02 , i.e. in the range commonly observed for low maturity type II kerogen. In contrast, this calculation gives a much higher " $\mathrm{S}_{\text {org }}$ " content for the chert kerogen, corresponding to an unusually high Sorg/C atomic ratio of 0.19 . In fact (i) XANES spectroscopy (G. Sarret, personal communication) showed that sulfur in the chert concentrate occurs almost exclusively as sulfate and (ii) $\mathrm{X}$-ray diffraction showed the presence of jarosite, an inorganic sulfate of general formula $\mathrm{KFe}_{3}\left(\mathrm{SO}_{4}\right)_{2}(\mathrm{OH})_{6}$ : main peaks $\left(2 \theta \mathrm{Co} K_{\alpha}\right)$ at 20.12, $20.95,22.52,24.89,27.60,28.29,30.23,33.98,38.40,43.57,48.45,51.74$ and 55.44). This sulfate can survive $\mathrm{HF} / \mathrm{HCl}$ treatment but is decomposed upon heating around $600{ }^{\circ} \mathrm{C}$, with $\mathrm{SO}_{2}$ production ([Mackenzie, 1970]). Indeed, the trace for the Curie-point flash pyrolysate at $610{ }^{\circ} \mathrm{C}$ of the chert concentrate (not shown) exhibits a prominent peak corresponding to sulfur 
dioxide that overwhelms the pyrolysis products of the kerogen. Due to the presence of jarosite in the concentrate, a significant value cannot be obtained for $\mathrm{S}_{\text {org }}$ content in the chert kerogen, using the elemental data and the classical calculation. In fact, the sulfur of jarosite is then taken into account in the total sulfur but not in the ash sulfur, due to jarosite decomposition and $\mathrm{SO}_{2}$ release upon heating during ash isolation. Hence, in that case, the value calculated for $\mathrm{S}_{\text {org }}$, by subtracting ash sulfur from total sulfur, is largely overestimated. Finally, it should be noted that jarosite can be formed by oxidation of pyrite. Therefore, the presence of jarosite in the chert concentrate must reflect the extensive oxidation that took place during chertification.

Table 2. Rock-Eval data and elemental composition for NN8c kerogen concentrate, NN8si kerogen concentrate and the $400{ }^{\circ} \mathrm{C}$ pyrolysis residue of the latter

\begin{tabular}{lccccccc}
\hline Sample & TOC $^{\mathrm{a}}$ & $\mathrm{HI}^{\mathrm{a}}$ & $\mathrm{OI}^{\mathrm{a}}$ & $\mathrm{H} / \mathrm{C}^{\mathrm{b}}$ & $\mathrm{O} / \mathrm{C}^{\mathrm{b}}$ & $\mathrm{Sorg} / \mathrm{C}^{\mathrm{b}}$ & $\mathrm{Ash}^{\mathrm{c}}$ \\
\hline SMB (NN8c) & $13.6^{\mathrm{d}}$ & $472^{\mathrm{e}}$ & $9^{\mathrm{e}}$ & $1.07^{\mathrm{d}}$ & $0.20^{\mathrm{d}}$ & $0.02^{\mathrm{d}}$ & $20.5^{\mathrm{d}}$ \\
SMB (NN8si) & 0.2 & $185^{\mathrm{e}}$ & $42^{\mathrm{e}}$ & 0.70 & 0.41 & $\mathrm{~ns}^{\mathrm{f}}$ & 5.8 \\
R400. NN8si & nd & nd & nd & 0.40 & 0.49 & $\mathrm{~ns}^{\mathrm{f}}$ & 11.0 \\
\hline
\end{tabular}

nd: pyrolysis residue not examined by Rock-Eval pyrolysis.

\subsubsection{Morphological features}

Light microscopy showed that the chert kerogen is mostly composed of amorphous OM (ca. $63 \%$ ) dominated by tiny (ca. $1 \mu \mathrm{m}$ ), brown, particles. A substantial contribution (ca. $31 \%$ ) of woody debris and a few microfossils, including some pollen and spores, was also detected. TEM observations did not reveal any structure in the tiny particles, which are composed of nanoscopically-amorphous OM. The clay kerogen showed a higher contribution (ca. 88\%) and much larger size (ca. $10 \mu \mathrm{m}$ ) for the amorphous particles, whereas the woody debris (ca. 9\%) and microfossils were less abundant.

\subsubsection{Spectroscopic features}

The solid state CP/MAS ${ }^{13} \mathrm{C}$ NMR spectrum of the chert kerogen (Fig. 2A) shows the presence of aliphatic carbons (0-60 ppm range, maximum around $30 \mathrm{ppm}$ corresponding to $\mathrm{CH}_{2}$ groups in polymethylenic chains), olefinic and/or aromatic unsaturations (peak centered at $130 \mathrm{ppm}$ ), $\mathrm{C}-\mathrm{O}$ groups (peak centered at $86 \mathrm{ppm}$ ) and $\mathrm{C}=\mathrm{O}$ in esters and/or amides (peak centered at $170 \mathrm{ppm}$ ). Comparison with the spectrum of the clay kerogen (Fig. 2B); ( [Salmon et al]) showed some quantitative differences for the chert kerogen: (i) an increase in the relative intensity of the peak at $170 \mathrm{ppm}$ corresponding to carboxyl groups, (ii) the occurrence of two maxima for the $\mathrm{C}-\mathrm{O}$ groups, including the peak at $86 \mathrm{ppm}$ probably related to aromatic carbons linked to oxygen and (iii) a larger shoulder around $40 \mathrm{ppm}$ probably corresponding to carbons adjacent to carbons bearing oxygen functions. Comparison of the FTIR spectra (not shown) showed a substantial shift in the maximum of the $\mathrm{C}=\mathrm{C}$ band $\left(1605\right.$ versus $\left.1615 \mathrm{~cm}^{-1}\right)$ for the chert kerogen, indicating a relatively higher contribution of aromatic unsaturations with respect to olefinic ones. The spectroscopic features therefore indicate a higher contribution of carboxyl groups and of aromatic units (including oxygen-substituted units) for the chert kerogen, in agreement with its higher $\mathrm{O} / \mathrm{C}$ and lower $\mathrm{H} / \mathrm{C}$ ratios (Table 2). 


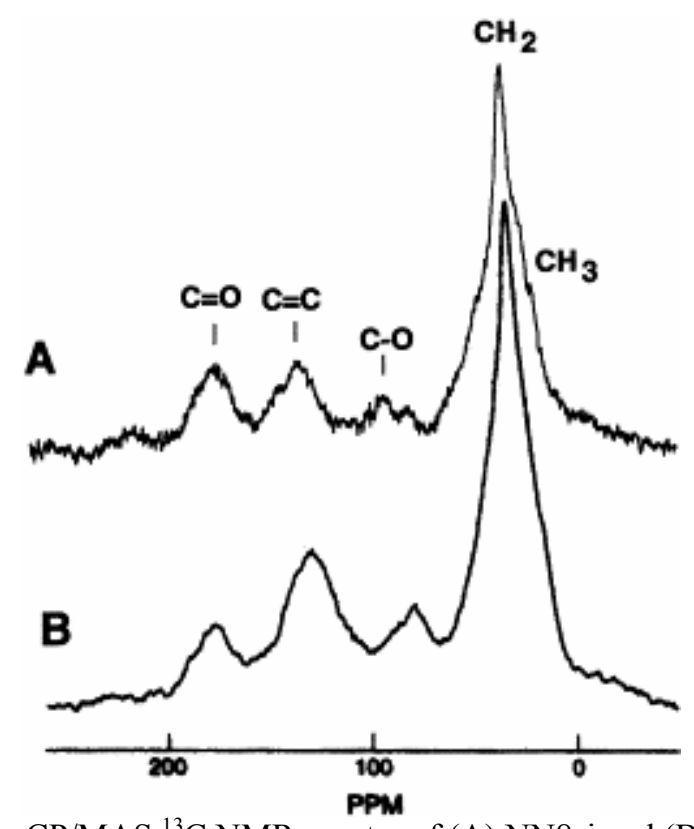

Fig. 2. Solid state CP/MAS ${ }^{13} \mathrm{C}$ NMR spectra of (A) NN8si and (B) NN8c kerogen.

\subsubsection{Pyrolysis}

Off-line pyrolysis at $400{ }^{\circ} \mathrm{C}$ resulted in a total weight loss of ca. $25 \%$ for the chert kerogen. The pyrolysis residue shows a decrease in the $\mathrm{H} / \mathrm{C}$ atomic ratio (Table 2), reflecting the release of the aliphatic moieties and the aromatization processes that led to the formation of this residual material. A higher weight loss (ca. 40\%) was previously observed, under the same pyrolysis conditions, for the clay kerogen ( [Salmon et al]) and the pyrolysis residue showed a higher $\mathrm{H} / \mathrm{C}$ atomic ratio (0.64 against 0.40$)$. Such differences should reflect the higher level of aromatic moieties in the chert kerogen, hindering the formation of volatile pyrolysis products and promoting the formation of residual polyaromatic material.

The GC trace of the crude pyrolysate of the chert kerogen showed a large unresolved complex mixture (UCM) of co-eluting compounds. The pyrolysate was, therefore, separated by column chromatography, into three fractions eluted with heptane, toluene and methanol, accounting for ca. 20, 15 and $50 \mathrm{wt} \%$ of the total pyrolysate, respectively. A large number of compounds, commonly found in kerogen pyrolysates were identified by GC/MS analysis of these three fractions, such as series of alkanes and alkenes, alkylated benzenes and alkylated polyaromatic hydrocarbons, hopanes and hopenes, $n$-alkanones and mid-chain ketones, fatty acids and phenols. Only the main differences in pyrolysate composition compared to the clay kerogen, previously examined by [Salmon et al] are presented below. These differences are chiefly related to the distribution of some pyrolysis products with long alkyl chains and of the phenols:

The abundant $n$-alkan-2-ones in the toluene-eluted fraction exhibit a bimodal distribution with maxima at $\mathrm{C}_{17}$ and $\mathrm{C}_{29}$ (Fig. 3) and the odd-carbon-numbered compounds predominate, whereas a unimodal distribution with a maximum at $\mathrm{C}_{13}$ followed by a rather smooth decrease in intensity and no odd-over-even predominance, was observed for the clay kerogen. This trend for a higher relative contribution of long-chain compounds exhibiting a marked predominance for the chert kerogen was also observed for the fatty acids, the $\mathrm{C}_{20+}$ homologues accounting for ca. $20 \%$ of the total fatty acids and exclusively corresponding to even-carbon-numbered compouds. 


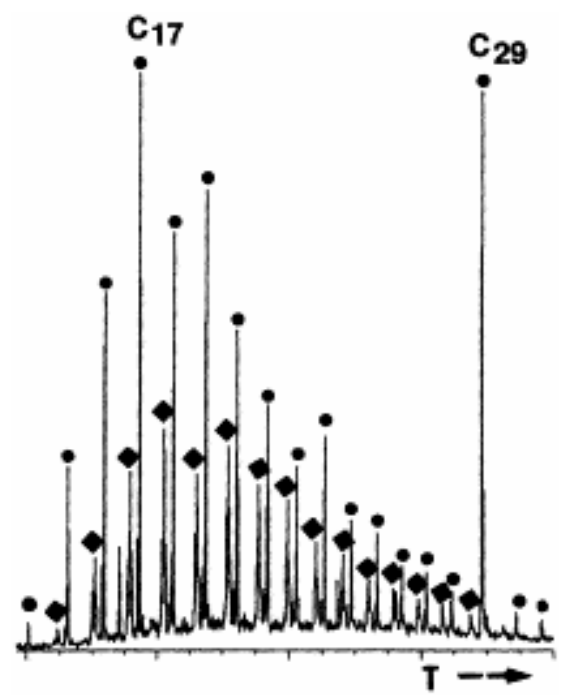

Fig. 3. Mass chromatogram at $m / z=58$ showing the distribution of the $n$-alkan-2-ones (filled circles) and of the co-eluting series of mid-chain ketones (filled diamonds) in the toluene-eluted fraction of the pyrolysate at $400{ }^{\circ} \mathrm{C}$ of NN8si kerogen (numbers refer to chain length).

The phenolic compounds in the pyrolysate of the chert kerogen correspond only to alkyl phenols, the $\mathrm{C}_{1}-\mathrm{C}_{3}$ homologues being predominant. In contrast, these short-chain phenols occur along with methoxy-substituted counterparts in the case of the clay kerogen.

The significance of these differences is discussed in the next section, in relation to the differences in the bulk, microscopic and spectroscopic features of the chert and clay kerogens.

\subsubsection{Comparison of chert and clay kerogens}

The OM in the clay and chert layers of mixed levels shares a common origin. Therefore, the compositional quantitative and qualitative differences observed between the clay and chert kerogens should reflect differences in post-depositional diagenesis associated with chert formation. Chertification resulted in extensive destruction of a large part of the initial OM in the silicified zone. This oxidative destruction is reflected in the chert kerogen by a sharp drop in the size of the brown amorphous particles, by the increase in $\mathrm{O} / \mathrm{C}$ atomic ratio and $\mathrm{OI}$ and by the marked decrease in HI and TOC. The latter decrease also reflects dilution resulting from chert production. In agreement with the generally higher resistance of terrestrial OM relative to marine OM and of palynomorphs relative to amorphous OM (e.g. [Tyson, 1995]), the woody debris and the microfossils were less affected by oxidative degradation than the brown amorphous material. As discussed below, this differential degradation that took place during chertification accounts for the marked morphological, spectroscopic and pyrolytic differences observed between the chert and clay kerogens.

\subsubsection{Microfossils}

The microfossils in both kerogens mostly correspond to pollen and spore walls. It is well documented that such microfossils contribute to kerogen formation through the "selective preservation" pathway, based on the existence of biomacromolecules exhibiting a very high resistance to diagenetic degradation (reviewed in [de Leeuw and Largeau, 1993 and Largeau and de Leeuw, 1995]). This type of biomacromolecule, when submitted to laboratory degradation experiments, also exhibits a high resistance to oxidative treatment (e.g. [Berkaloff 
et al]). Thus, the pollen and spore walls that occurred in the kerogen of the clayey zone that was transformed into chert were not highly affected by the oxidation processes associated with chertification; hence the enrichment observed for these microfossils in the chert kerogen.

Generally, these resistant biomacromolecules are highly aliphatic and their pyrolysates show the abundant presence of $n$-alkanones, derived from the thermal cleavage of ether cross-links. Such ketones show a typical distribution that reflects the location of the ether links on specific positions of the alkyl chains, this location being biosynthetically controlled (e.g. [Derenne et al, Derenne et al, Gillaizeau et al, Gelin et al, Gelin et al, Schouten et al and Blokker et al]). The $n$-alkan-2-ones that abundantly occur in the pyrolysate of the chert kerogen exhibit a bimodal $\left(\mathrm{C}_{17}, \mathrm{C}_{29}\right)$ distribution (Fig. 3), with a sharp maximum at $\mathrm{C}_{29}$. This bimodal distribution reflects a marked preferential location of the ether linkages on the alkyl chains for the kerogen moieties from which these ketones are generated by pyrolysis. The distribution of these $n$-alkan-2-ones thus probably reflects, in agreement with microfossil enrichment, the substantial contribution of resistant aliphatic biomacromolecules in the chert kerogen. These components afforded a much lower contribution to the clay kerogen so that such features were not observed due to large dilution by the pyrolysis products of the other fractions. In contrast, as a result of the extensive destruction that took place during chertification, the aliphatic biomacromolecules were enriched and their typical signature could now be observed. Moreover, the preferential location of the ether bridges suggests that such components did not undergo substantial alteration during chertification since, as discussed below, oxidative alteration is reflected in a random location of the oxygen-containing bridges.

\subsubsection{Woody debris}

Complete degradation of lignin into soluble compounds can hardly be achieved through strong oxidative laboratory treatments ([Isherwood, 1965]) and lignin also shows a high resistance to diagenetic degradation. Short chain $\left(\mathrm{C}_{1}-\mathrm{C}_{3}\right)$ alkyl phenols and methoxysubstituted alkyl phenols are typical pyrolysis products of lignin (e.g. [Saiz-Jimenez and de Leeuw, 1986 and Hatcher and Spiker, 1988]). $\mathrm{C}_{1}-\mathrm{C}_{3}$ Alkyl phenols and methoxy-substituted alkyl phenols were observed in pyrolysate of the clay kerogen, in agreement with the contribution of woody debris. The relative abundance of such debris is substantially higher in the chert kerogen and the isomers of methylphenol and several isomers of dimethylphenol, probably related to lignin, were detected in its pyrolysate. In contrast to the clay kerogen, however, no methoxy-substituted phenols were observed. It is well documented (e.g. [Hatcher and Clifford, 1997]) that lignin alteration results in demethoxylation reactions. Thus, it appears that lignin was enriched during chertification but the retained lignin underwent some alteration through elimination of the methoxy groups.

\subsubsection{Amorphous OM}

Despite the increase in the relative contribution of microfossils and woody debris, amorphous particles still dominate the chert kerogen. As previously shown ([Salmon et al]), the bulk of the amorphous particles in the clay kerogen originated from the condensation of potentially labile compounds that survived diagenesis owing to mineral protection provided by alternation of organic and clay nanolayers. The kerogen fractions thus formed are highly sensitive to oxidative degradation, once this physical protection is removed by destruction of the mineral nanolayers. Indeed, the isolated clay kerogen undergoes pronounced and fast oxidative alteration upon storage, when exposed to air at room temperature ( [Salmon et al]). Such a high sensitivity accounts for the extensive degradation that took place, for the 
amorphous fraction of the clay kerogen, when submitted to the oxidative conditions associated with chertification. Moreover, the low amount of this amorphous material that escaped destruction probably underwent major alteration in chemical structure, as reflected by the high level of oxygen-containing groups occurring in the chert kerogen. This alteration possibly resulted in the formation of resistant macromolecular compounds with a high degree of oxygen cross-linking. As recently shown ( [Riboulleau et al and Riboulleau et al]), such cross-linking was implicated in the formation of some kerogens and "oxidative reticulation" was thus put forward as a new pathway of OM preservation in sediments. A similar process may therefore account for the lack of complete destruction of the "oxidation-sensitive" amorphous material in the chert kerogen. The occurrence of oxidative cross-linking is supported by the presence in the pyrolysate of several series of "mid-chain" $n$-alkanones with the keto group located on any carbon atom from $\mathrm{C}(3)$ to $\mathrm{C}(12)$. Contrary to the $n$-alkan-2-ones these series showed a smooth distribution (Fig. 3), indicating the lack of preferential location of the corresponding ether bridges on the alkyl chains. Such a random location of the bridges would be typical of the materials formed by oxidative reticulation ( [Riboulleau et al and Riboulleau et al]). The preservation of this amorphous fraction by oxidative reticulation is consistent with the relatively high OI and the relatively low HI values observed for the chert sample, as typical for all samples of this type in the black levels of the basin.

\section{Conclusion}

Rock-Eval analysis of a large set of samples from three sections confirmed the occurrence of compositional differences in OM abundance and quality between clay and chert samples. The low TOC and the low oil potential typical of the latter must reflect the large oxidative destruction of the initial kerogen that took place during chertification.

Different levels of destruction occurred between the various fractions of the initial kerogen in the silicified NN8 layer, as reflected by an increase in the relative contribution of the microfossils and woody debris. Moreover, pyrolytic signatures suggest that the microfossil components did not undergo significant alteration during chertification, whereas the chemical structure of lignin in the retained woody debris was substantially altered due to demethoxylation.

The amorphous particles, physically protected by clay mineral nanolayers in the initial kerogen, were extensively destroyed during chertification so that their relative contribution decreased while remaining predominant. The amorphous OM retained in the chert kerogen showed major changes in chemical structure due to substantial incorporation of oxygen. This probably reflects the oxidative reticulation that allowed a small part of the amorphous OM to escape destruction during chertification.

The differential processes that extensively affected the initial, clayey, material during chertification account for the morphological and chemical features of the chert kerogen and the differences in $\mathrm{OM}$ abundance and oil potential, which are systematically observed between the chert and clay samples in the black levels of the Umbria-Marche Basin.

We wish to thank Y. Pouet (ENSCP, Paris) for performing GC/MS and combined Curie-point Py/GC/MS analyses and C. Clinard (CRMD, Orléans) for technical assistance for TEM observations. Drs. François Baudin (Université Pierre et Marie Curie, Paris) and Nicolas Tribovillard (Université de Lille) are acnowledged for helpful information on jarosite. Dr. R. Tyson, an anonymous referee and the Associate Editor are thanked for detailed and constructive comments. 


\section{References}

Arthur and Premoli, 1982. M.A. Arthur and I. Premoli Silva, Development of widespread organic carbon-rich strata in the Mediterranean Tethys. In: S.O. Schlanger and M.B. Cita, Editors, Nature and Origin of Cretaceous Carbon-rich facies, Academic Press, New York (1982), pp. 9-54.

Beaudoin et al., 1996. B. Beaudoin, E.P. M'Ban, A. Montanari and M. Pinault, Lithostratigraphie haute résolution $(<20 \mathrm{ka})$ dans le Cénomanien du bassin d'Ombrie-Marches (Italie). Comptes Rendus de l'Académie des Sciences Paris 323 Series Iia (1996), pp. 689696.

Behl, 1990. R.J. Behl, Mixing of biogenic siliceous and terrigenous clastic sediments: South Belridge Field and Beta Field, California. American Association of Petroleum Geologists Bulletin 74 (1990), pp. 760-781.

Berkaloff et al., 1983. C. Berkaloff, E. Casadevall, C. Largeau, P. Metzger, S. Peracca and J. Virlet, The resistant polymer of the walls of the hydrocarbon-rich alga Botryococcus braunii. Phytochemistry 22 (1983), pp. 389-397.

Blokker et al., 2000. P. Blokker, S. Schouten, J.W. de Leeuw, J.S. Sinninghe Damsté and H. van den Ende, A comparative study of fossil and extant algaenans using ruthenium tetroxide degradation. Geochimica et Cosmochimica Acta 64 (2000), pp. 2055-2065.

de Boer and Smith, 1994. P.L. de Boer and D.G. Smith, Orbital forcing and cyclic sequences. Special Publication of the International Association of Sedimentologists 19 (1994), pp. 1-14.

Boussafir et al., 1994. M. Boussafir, E. Lallier-Vergès, P. Bertrand and D. Badaut-Trauth, Structure ultrafine de la matière organique des roches mères du Kimméridgien du Yorkshire. Bulletin de la Société Géologique de France 165 (1994), pp. 355-363.

Derenne et al., 1992. S. Derenne, C. Largeau and P.G. Hatcher, Structure of Chlorella fusca algaenan-Relationships with ultralaminae in lacustrine kerogens. Species- and environmentdependent variations in the composition of fossil ultralaminae. Organic Geochemistry 18 (1992), pp. 417-422.

Derenne et al., 1997. S. Derenne, C. Largeau, M. Hetényi, A. Brukner-Wein, J. Connan and B. Lugardon, Chemical structure of the organic matter in a Pliocene maar-type oil shale. Implicated Botryococcus races and formation pathways. Geochimica et Cosmochimica Acta 61 (1997), pp. 1879-1889.

Durand and Nicaise, 1980. B. Durand and G. Nicaise, Procedures for kerogen isolations. In: B. Durand, Editor, Kerogen, Technic, Paris (1980), pp. 35-53.

Espitalié et al., 1980. J. Espitalié, M. Madec and B. Tissot, Role of mineral matrix in kerogen pyrolysis; influence on petroleum generation and migration. American Association of Petroleum Geologists Bulletin 64 (1980), pp. 59-66. 
Espitalié et al., 1985. J. Espitalié, G. Deroo and F. Marquis, La pyroloyse Rock-Eval et ses applications; deuxième partie. Revue de l'institut Français du Pétrole 40 (1985), pp. 755-784.

Gelin et al., 1996. F. Gelin, I. Boogers, A.A.M. Nooderloos, J.S. Sinninghe Damsté, P.G. Hatcher and J.W. de Leeuw, Novel, resistant microalgal polyethers: an important sink in the marine environment?. Geochimica et Cosmochimica Acta 60 (1996), pp. 1275-1280.

Gelin et al., 1999. F. Gelin, J.K. Volkman, C. Largeau, S. Derenne, J.S. Sinninghe Damsté and J.W. de Leeuw, Distribution of aliphatic, nonhydrolysable biopolymers in marine microalgae. Organic Geochemistry 30 (1999), pp. 147-159.

Gillaizeau et al., 1996. B. Gillaizeau, S. Derenne, C. Largeau, C. Berkaloff and B. Rousseau, Source organisms and formation pathway of the kerogen of the Göynük Oil Shale (Oligocene, Turkey) as revealed by electron microscopy, spectrometry and pyrolysis. Organic Geochemistry 24 (1996), pp. 671-679.

Hatcher and Clifford, 1997. P.G. Hatcher and D.J. Clifford, The organic geochemistry of coal: from plant materials to coal. Organic Geochemistry 33 (1997), pp. 181-188.

Hatcher and Spiker, 1988. P.G. Hatcher and E.C. Spiker, Selective degradation of plant biomolecules. In: F.H. Frimmel and R.F. Christman, Editors, Humic Substances and Their Role in the Environments, Wiley, New York (1988), pp. 59-74.

Isherwood, 1965. F.A. Isherwood, Biosyntheis of lignin. In: J.B. Pridham and T. Swain, Editors, Biosynthetic Pathways in Higher Plants, Acadamic Press, London (1965), pp. 133146.

Klemme and Ulmishek, 1991. H.D. Klemme and G.F. Ulmishek, Effective petroleum source rocks of the world: stratigraphic distribution and controlling depositional factors. American Association of Petroleum Geologists Bulletin 75 (1991), pp. 1809-1851.

Largeau and de Leeuw, 1995. C. Largeau and J.W. de Leeuw, Insoluble, non-hydrolysable, aliphatic macromolecular constituents of microbial cell walls. In: J. Gwynfryn Jones, Editor, Advances in Microbial Ecology 14, Plenum Press, New York (1995), pp. 77-118.

Largeau et al., 1986. C. Largeau, S. Derenne, E. Casadevall, A. Kadouri and N. Sellier, Pyrolysis of immature Torbanite and of the resistant biopolymer (PRB A) isolated from extant alga Botryococcus braunii. Mechanism of formation and structure of Torbanite. In: D. Leythaeuser and J. Rullkötter, Editors, Advances in Organic Geochemistry, 1985, Organic Geochemistry 10, Pergamon Press, Oxford (1986), pp. 1023-1032.

de Leeuw and Largeau, 1993. J.W. de Leeuw and C. Largeau, A review of macromolecular organic compounds that comprise living organisms and their role in kerogen, coal and petroleum formation. In: M.H. Engel and S.A. Macko, Editors, Organic Geochemistry, Plenum Press, New York (1993), pp. 23-72.

Mackenzie, 1970. R.C. Mackenzie, Differential Thermal Analysis. Vol. 1: Fundamental Aspects. , Academic Press, London (1970). 
Marcellari and de Vries, 1987. C.E. Marcellari and T.J. de Vries, Late Cretaceous upwelling and anoxic sedimentation in Northwestern South America. Palaeogeography, Palaeoclimatology and Palaeoecology 59 (1987), pp. 279-292.

M'ban, 1994. M'ban, E.P., 1994. Evolution de la sédimentation pélagique au Crétacé supérieur des Marches et de l'Ombrie (Italie Centrale). Litho- Biostratigraphie, Géochimie, Paléoenvironnement. Thèse de Doctorat de l'Université Pierre et Marie Curie, Paris, pp. 256.

Oehler, 1976. J.H. Oehler, Experimental studies in Precambrian palaeontology: structural and chemical changes in blue-green algae during fossilisation in synthetic chert. Geological Society of America Bulletin 87 (1976), pp. 117-129.

Riboulleau et al., 2000. A. Riboulleau, S. Derenne, G. Sarret, C. Largeau, F. Baudin and J. Connan, Pyrolytic and spectroscopic study of a sulphur-rich kerogen from the "Kashpir oil shales" (Upper Jurassic, Russian Platform). Organic Geochemistry 31 (2000), pp. 1641-1661.

Riboulleau et al., 2001. A. Riboulleau, S. Derenne, C. Largeau and F. Baudin, Origin of contrasted features and preservation pathways in kerogens from the Kashpir oil shales (Upper Jurassic, Russian Platform). Organic Geochemistry 32 (2001), pp. 647-665.

Saiz-Jimenez and de Leeuw, 1986. C. Saiz-Jimenez and J.W. de Leeuw, Lignin pyrolysis products: their structure and their significance as biomarkers. Organic Geochemistry 10 (1986), pp. 869-876.

Salmon et al., 1997. V. Salmon, S. Derenne, C. Largeau, B. Beaudoin, G. Bardoux and A. Mariotti, Kerogen chemical structure and source organisms in a Cenomanian organic-rich black shale (Central Italy) -Indications for an important role of the "sorptive protection" pathway. Organic Geochemistry 27 (1997), pp. 423-438.

Salmon, 1999. Salmon, V., 1999. Modes d'accumulation de la matière organique dans des "black shales" et des silex du Cénomanien d'Italie Centrale. Thèse de Doctorat de l'Ecole des Mines de Paris, Paris, pp. 242.

Salmon et al., 2000. V. Salmon, S. Derenne, E. Lallier-Vergès, C. Largeau and B. Beaudoin, Protection of organic matter by mineral matrix in a Cenomanian black shale. Organic Geochemistry 31 (2000), pp. 463-474.

Schouten et al., 1998. S. Schouten, P. Moerkerken, F. Gelin, M. Baas, J.W. de Leeuw and J.S. Sinninghe Damsté, Structural characterization of aliphatic, non-hydrolysable biopolymers in freshwater algae and a leaf cuticle using ruthenium tetroxide degradation. Phytochemistry 49 (1998), pp. 987-993.

Tissot and Welte, 1984. B.P. Tissot and D.H. Welte, Petroleum, Formation and Occurrence. , Springer, Berlin (1984).

Tyson, 1995. R.V. Tyson, Sedimentary Organic Matter., Chapman, London (1995). 